\title{
Evaluation of Six Sample Preparation Methods for Determination of Trace Metals in Lubricating Oils Using Inductively Coupled Plasma-Optical Emission Spectrometry
}

\author{
Haile A. Tekie ${ }^{a}$, Robert I. McCrindle ${ }^{a, *}$, Pieter J.J.G. Marais ${ }^{a}$ \& Abayneh A. Ambushe ${ }^{b}$ \\ ${ }^{a}$ Department of Chemistry, Tshwane University of Technology, P.O Box 56208, Arcadia, Pretoria, 0007, South Africa. \\ ${ }^{b}$ Department of Chemistry, University of Limpopo, Private Bag X1106, Sovenga, 0727, South Africa.
}

Received 14 November 2014, revised 8 April 2015, accepted 10 April 2015.

\begin{abstract}
Dedicated to the late Prof. P.J.J.G. Marais
ABSTRACT

Quantification of trace elements in used lubricating oil forms a vital part in monitoring engine conditions and impact on the environment. In this study, inductively coupled plasma-optical emission spectrometry (ICP-OES) was employed for the determination of $\mathrm{Ag}, \mathrm{Ba}, \mathrm{Cu}, \mathrm{Mn}$ and $\mathrm{Ni}$ in used lubricating oils. Methodology was developed so as to minimize the oil's carbonaceous matter and its effect on viscosity. Accordingly, six oil sample preparation techniques (xylene dilution, detergent emulsion, microwave digestion, dry-ashing, wet-ashing and ultrasonic extraction) were investigated for their efficiency. Optimization of the factors influencing ultrasonic-assisted extraction and ICP-OES operating parameters enabled quantification of the trace metals in oils. Limits of detection $\left(3 S_{\mathrm{b}} / \mathrm{m}\right)$, in the $\mathrm{ng}^{-1}$ range, were obtained for each element of interest using each method investigated. The validity of the methodologies studied was confirmed through the analysis of quality control (QC) samples. Analyte recoveries, ranging from 48.3 to $106 \%$, were obtained. Evaluation of the analytical methods studied with regard to accuracy, precision, LOD, linearity, applicability for routine analysis, preparation time and cost was made. Based on these evaluations, ultrasonic extraction has a clear advantage in terms of accuracy, applicability for routine analysis, time and cost of sample preparation.
\end{abstract}

KEYWORDS

Lubricating oil, ICP-OES, optimization.

\section{Introduction}

Trace metals in lubricating oils are generated from additive metals, wear particles ${ }^{1-3}$ and contaminants. ${ }^{2-4}$ Premium quality base oils are usually blended with organo-metallic compounds of $\mathrm{Ba}, \mathrm{Ca}, \mathrm{Mg}{ }^{1,5,6} \mathrm{Mo}, \mathrm{P}, \mathrm{Zn},{ }^{1,5} \mathrm{Cd}, \mathrm{Co}, \mathrm{Cr}, \mathrm{Fe}, \mathrm{Hg}$, Ni, S, Sb, Se, Sn and $\mathrm{Ti}$ to enhance the performance of the lubricant and its properties. ${ }^{1}$ Mechanical erosion of moving parts usually introduces wear metals into the oil circulation. ${ }^{3}$ These wear products are composed of the same material as the metal surfaces from which they originated. During normal operation, wearing is inevitable. However, excessive friction causes premature wear, which results in significant economic loss. ${ }^{2,7}$ Any unwanted substance ingress into the oil is considered a contaminant. The most common oil contaminants include: particle, sand, moisture, dust, glycol, slag, soot and fuel. ${ }^{4}$ A recent study by Nissan motors of Japan reported that $85 \%$ of hydraulic failures were due to oil contamination. ${ }^{4,8}$

Quantitative determination of trace metals in used oil serves as a diagnostic tool for engine and turbine faults. ${ }^{1,7}$ Currently, regular oil testing forms an integral part of a maintenance plan for shipping, aviation, oil refineries, mining, processing and chemical plants. ${ }^{8}$ Used oil analysis is thus used to perform preventive maintenance, ${ }^{4,6,7}$ replacement of components, ${ }^{7}$ predictive maintenance ${ }^{4,5}$ and control the quality of oil additives. ${ }^{5}$ However, lubricating oil analysis is often a difficult task due to its matrix complexity, viscosity and high organic content. ${ }^{1,5,6,9}$ Hence, analytical techniques with greater sensitivity are required for oil analysis. Spectrometric techniques such as flame-atomic absorp-

* To whom correspondence should be addressed: E-mail: mccrindleri@tut.ac.za tion spectrometry (F-AAS), graphite furnace-atomic absorption spectrometry (GF-AAS) and inductively coupled-optical emission spectrometry (ICP-OES) have been widely used for oil analysis. ${ }^{10}$ In this report, ICP-OES was selected for its good limit of detection (LOD), better precision and repeatability, wider linear dynamic range ${ }^{7}$ and sequential multi-element analysis. ${ }^{11}$

Most analytical techniques require the sample for analysis to be in solution form. This solution should not contain high levels of insoluble particles and it should not be viscous. ${ }^{2}$ Samples with high organic load affect the plasma stability, increase background emission and reduce the energy suitable for ionization and excitation. ${ }^{7}$ Unfortunately, most preparation methods for oils are labour-intensive and time-consuming, particularly for large sample numbers. ${ }^{2}$ Consequently, $60 \%$ of the total time required for analysis is spent in sample preparation and this accounts for $30 \%$ of the total analysis error. ${ }^{12,13}$

Several oil sample preparation techniques are proposed in the literature, including: oil dilution, oil-in-water emulsification, microwave digestion, ${ }^{1,2,5,7,14}$ dry-ashing, ${ }^{1,2,5,14}$ wet-ashing ${ }^{2,6}$ and ultrasound-assisted extraction. ${ }^{15}$ The traditional oil dilution, using organic solvents, is convenient for rapid estimation of indicator metals. Xylene and kerosene have been widely used as typical solvents with ICP-OES. ${ }^{2}$ Oil-in-water emulsion, which employs a surfactant, converts the oil sample into homogenously dispersed micro-droplets in an aqueous phase. A homogenously dispersed emulsion behaves similar to an aqueous solution and allows aqueous standards for calibration. ${ }^{1,6,7,11}$ Microwave digestion is carried out in closed and pressurized vessels, employing various acids or acid mixtures. ${ }^{16}$ Digestion, using nitric acid at 
elevated temperature and pressure can rapidly decompose the oil matrix. ${ }^{17}$ Dry-ashing, which is carried out under normal air pressure in a muffle furnace, ensures that the organic matrix is completely mineralized and the total metal content is converted to simple water-soluble species. ${ }^{2,6}$ The wet-ashing technique, which is based on ignition of the organic material at high temperature and involves the use of strong acids and normal air pressure, also completely destroys the organic matrix. ${ }^{2}$ Ultrasonic energy, generated from an ultrasonic bath, is an alternative means of analyte extraction from a number of sample types. ${ }^{15,18}$ The volume of the water bath, sample position, percentage of detergent in the bath, and the bath temperature, are some of the most important variables that should be monitored. ${ }^{15}$ The objective of the study was to compare and evaluate the efficiencies of six analytical methods (xylene dilution, oil emulsification, microwave digestion, dry- and wet-ashing and ultrasonic extraction) used for the determination of trace metals in lubricating oils.

\section{Experimental}

\subsection{Reagents and Standards}

High purity doubly-deionized water, obtained using a Millipore Milli-Q deionizer (Millipore, Bedford, MA, USA), was used to prepare solutions. Analyzed Analytical Reagent (AAR) grade $\mathrm{HNO}_{3}(65 \%), \mathrm{H}_{2} \mathrm{O}_{2}(30 \%), \mathrm{HCl}(32 \%), \mathrm{H}_{2} \mathrm{SO}_{4}(98.08 \%)$ and xylene (SMM Instruments (Pty) Ltd, South Africa) were used. A non-ionic surfactant (Triton X-100) obtained from Merck (Darmstadt, Germany) was used for detergent formation. Aqueous working standards were prepared from $1000 \mathrm{mg} \mathrm{kg}^{-1}$ multielement stock solution, containing $\mathrm{Ag}, \mathrm{Ba}, \mathrm{Cu}, \mathrm{Mn}$ and $\mathrm{Ni}$ in $5 \% \mathrm{HNO}_{3}$ (Teknolab AB, Kolbotn, Norway). Organo-metallic standard (Conostan S-21, Conoco Specialty Products Inc., Ponca City, OK, USA), with analyte concentration of $500 \mathrm{mg} \mathrm{kg}^{-1}$ in oil, was used for xylene dilution method. EnviroMAT, used oil certified reference material (CRM), HU-1 (SCP SCIENCE, Quebec, Canada) was used to check the accuracy of methods. Oil samples were collected from a local service station.

\subsection{Instrumentation and Apparatus}

Analysis of used lubricating oil for trace metals was carried out using a simultaneous Spectro Arcos ICP-OES with radial plasma viewing (Spectro Instruments, Kleve, Germany). The ICP-OES utilizes 32 linear CCD detectors in a Paschen-Runge mount. All ICP-OES-based analyses were monitored by Spectro Smart Analyser Vision Software (version 4.01) (Spectro Instruments, Kleve, Germany). The ICP-OES operational parameters employed are given in Table 1.

A MARS 5 microwave digestion system (CEM Corporation,
USA) was employed for lubricating oil digestion. It was equipped with ESP-1500 plus pressure and RTP-300 plus temperature control systems. Teflon EasyPreps vessels, allowing a maximum decomposition pressure of 800 psi at $240{ }^{\circ} \mathrm{C}$ were used to digest the oils. An ultrasonic bath (Ultrasons, J.P. Selecta, Barcelona, Spain) was used for the ultrasound-assisted extraction and agitation of oil samples. Instrument operating parameters, like the intensity of the ultrasonic energy and temperature, were monitored by company default. Volumetric flasks of $100 \mathrm{~mL}$ were used as reaction vessels and placed at selected locations in the bath using burette supports.

\subsection{Sample Preparation}

\subsubsection{Oil Dilution Procedure}

A mass of $2.00 \mathrm{~g}$ used oil was accurately weighed and diluted to a final mass of $40.0 \mathrm{~g}$ with xylene. For calibration, appropriate quantities of organo-metallic standards were accurately weighed and made up to $2.00 \mathrm{~g}$ with base oil 75 , after which diluted to $40.0 \mathrm{~g}$ with xylene. The CRM was also prepared in a similar manner as the working standards. In all analyzed solutions, the oil content was kept at $5 \%$, aiming to match the viscosities.

\subsubsection{Oil Emulsification Procedure}

Oil-in-water emulsions were prepared employing a specific sequence to guarantee their homogeneity and stability. An aliquot of $0.500 \mathrm{~g}$ used oil was placed in a $25.0 \mathrm{~mL}$ volumetric flask and $0.500 \mathrm{~mL}$ concentrated nitric acid was added aiming to dissolve some metals. The mixture was then agitated in an ultrasonic bath for $5 \mathrm{~min}$ followed by the addition of $1.00 \mathrm{~g}$ Triton X-100 to stabilize the oil-in-water emulsion. The resulting mixture was then shaken gently, after which doubly-deionized water was added, under continuous agitation, until a final mass of $10.0 \mathrm{~g}$ was obtained. The resulting mixture was finally shaken vigorously and agitated in an ultrasonic bath for $5 \mathrm{~min}$ to homogenize the contents. Calibration standards were prepared in a similar manner as the real samples, but using the required quantity of inorganic standard.

\subsubsection{Microwave Digestion Procedure}

An aliquot of used oil $(0.200 \mathrm{~g})$ was accurately weighed into an EasyPreps vessel liner. After addition of $4.00 \mathrm{~mL}$ nitric acid, the vessels were subjected to digestion based on the MARS 5 ramp-to-temperature heating programme of 1600 maximum power, $30 \mathrm{~min}$ ramp, $800 \mathrm{psi}$ pressure, $200^{\circ} \mathrm{C}$ maximum temperature and $10 \mathrm{~min}$ hold time. In each batch, six vessels were used for simultaneous digestion. The resulting digested material was then transferred to a pre-cleaned high density polypropylene (HDPP) vessel, and diluted to $20.0 \mathrm{~g}$ with doubly-deionized water.

Table 1 Optimized operational conditions employed for ICP-OES analysis.

\begin{tabular}{|c|c|c|}
\hline \multirow[t]{2}{*}{ ICP parameter } & \multicolumn{2}{|c|}{ Sample matrix } \\
\hline & Aqueous & Organic \\
\hline Forward RF Power (W) & 1359 & 1540 \\
\hline Coolant gas flow rate $\left(\mathrm{L} \mathrm{min}^{-1}\right)$ & 13 & 17 \\
\hline Auxiliary gas flow rate $\left(\mathrm{L} \mathrm{min}^{-1}\right)$ & 0.9 & 2.21 \\
\hline Nebulizer flow rate $\left(\mathrm{L} \mathrm{min}^{-1}\right)$ & 0.9 & 0.82 \\
\hline Observation height (mm) & -10 & 0 \\
\hline Signal integration time (s) & 30 & 30 \\
\hline Peristaltic pumping rate (rpm) & 30 & 30 \\
\hline Spray Chamber & Scott type & \\
\hline Nebulizer & Cross flor & \\
\hline Torch type & Fixed one & \\
\hline
\end{tabular}




\subsubsection{Dry-ashing Procedure}

A mass of $2.00 \mathrm{~g}$ used lubricating oil was accurately weighed in a porcelain crucible and heated on a hot plate until completely dried. The dried sample was then exposed to a two stage muffle furnace heating programme until completely ashed: $450{ }^{\circ} \mathrm{C}$ for $11 \mathrm{~h}$ (overnight) and $550{ }^{\circ} \mathrm{C}$ for $1.5 \mathrm{~h}$. The resulting ash was then dissolved in $2.00 \mathrm{~mL}$ concentrated nitric acid and finally diluted to $40.0 \mathrm{~g}$ with Milli-Q water.

\subsubsection{Wet-ashing Procedure}

A mass of $2.00 \mathrm{~g}$ used lubricating oil was accurately weighed in a porcelain crucible. After additions of $2.00 \mathrm{~mL}$ sulphuric acid, the sample was subjected to heating on hot plate until completely dried. For Ba analysis, $1.50 \mathrm{~mL}$ of nitric acid was used in place of sulphuric acid, which was introduced dropwise to minimize sample splashing and foaming. The dried sample was then subjected to a two-stage muffle furnace heating programme until completely ashed: $450^{\circ} \mathrm{C}$ for $2 \mathrm{~h}$ and $550{ }^{\circ} \mathrm{C}$ for another $2 \mathrm{~h}$. The resulting ash was then dissolved in $1.50 \mathrm{~mL}$ concentrated $\mathrm{HNO}_{3}$, and finally diluted up to $40.0 \mathrm{~g}$ with Milli-Q water.

\subsubsection{Ultrasound-assisted Extraction Procedure}

A mass of $2.00 \mathrm{~g}$ used lubricating oil was accurately weighed and placed in a pre-cleaned $100 \mathrm{~mL}$ volumetric flask. An optimized amount of extractant solution $(10 \mathrm{~mL}$ aqua regia $)$ was then added and the resulting mixture irradiated at the optimum sonication time of 120 min to guarantee maximum sample irradiation, the volumetric flasks were kept stationary at selected positions in the bath and only four samples were used for simultaneous sonication. The resulting supernatant liquid was separated from the solid phase by centrifugation at $2500 \mathrm{rpm}$ for $15 \mathrm{~min}$ after which diluted up to $40.0 \mathrm{~g}$ with Milli-Q water.

\subsection{Factorial Optimization of Ultrasound-assisted Extraction Conditions}

Ultrasonic energy, generated from an ultrasonic bath, was thoroughly studied for its capability to extract analytes of interest in used lubricating oil samples. A full factorial experimental design of $4^{3}$ with 64 runs was proposed to study the effects of sonication time, extractant solution ratio and volume. The extracting solutions selected for this study were nitric and hydrochloric acids and hydrogen peroxide in different proportions, as shown in Table 2. Maximum analyte recovery was used as a response criterion and the three factors along with the four levels as control variables for the optimization scheme. Mass of oil ( $2 \mathrm{~g})$, volume of water bath $(2000 \mathrm{~mL})$ and detergent content of the bath $(2 \%, \mathrm{v} / \mathrm{v})$ were kept constant throughout the optimization scheme.

Table 2 Factors and levels used in the full factorial experimental design $\left(4^{3}\right)$ of the ultrasonic extraction scheme.

\begin{tabular}{lcccc}
\hline Factors & \multicolumn{3}{c}{ Levels } \\
\hline Sonication time $(\mathrm{min})$ & 30 & 60 & 90 & 120 \\
Acids mixture ratio $\left(\mathrm{HNO}_{3}: \mathrm{H}_{2} \mathrm{O}_{2}: \mathrm{HCl}, \mathrm{v} / \mathrm{v}\right)$ & $2: 1: 0$ & $1: 0: 0$ & $1: 0: 1$ & $1: 0: 3$ \\
Volume of acid mixture $(\mathrm{mL})$ & 3 & 6 & 8 & 10 \\
\hline
\end{tabular}

\section{Results and Discussion}

\subsection{Optimization of Ultrasound-assisted Extraction}

Sonication of used oil samples applying the full factorial design $\left(4^{3}\right)$ produced a supernatant solution, which could easily be aspirated into the plasma. Analysis of the supernatant solution by ICP-OES, employing aqueous calibration standards, gave quantifiable data. These data were used to compute the recovery efficiency of each experimental condition, which finally used as criteria for deciding the optimum extraction conditions. Thus, sonicating $2.00 \mathrm{~g}$ used oil sample in $10.0 \mathrm{~mL}$ aqua regia for $120 \mathrm{~min}$ was found to be the optimum extraction condition for the elements studied.

\subsubsection{Influence of Nitric Acid}

Used oils sonicated with nitric acid alone appeared yellow in colour and gave poor recoveries for $\mathrm{Ag}(1.70-4.50 \%)$ and $\mathrm{Ba}$ (15.9-79.9\%). However, it gave an enhanced extraction of $\mathrm{Cu}$, $\mathrm{Mn}$ and $\mathrm{Ni}$, with recoveries ranged from 52.3 to $106 \%$. Based on the calculated Pearson correlation coefficient ( $\mathrm{r}$ ), increasing the volume of nitric acid from 3 to $10 \mathrm{~mL}$, while the sonication time was kept constant at $30 \mathrm{~min}$, had a negative effect for the extraction of the elements studied, except for Ni. On the other hand, a simultaneous increase in the volume of nitric acid $(3.00-10.0 \mathrm{~mL})$ and sonication time (30-90 $\mathrm{min}$ ) promoted a strong positive effect for all elements studied.

\subsubsection{Influence of $\mathrm{HNO}_{3}: \mathrm{H}_{2} \mathrm{O}_{2}(2: 1, v / v)$}

Used oil samples extracted with $\mathrm{HNO}_{3}: \mathrm{H}_{2} \mathrm{O}_{2}(2: 1, \mathrm{v} / \mathrm{v})$ appeared pale yellow in colour and had an almost similar extraction effect when compared with using nitric acid alone. This extracting reagent yielded good recoveries of $\mathrm{Cu}, \mathrm{Mn}$ and $\mathrm{Ni}$ ranged from 74.6 to $105 \%$; but poor recoveries of $\mathrm{Ag}$ and $\mathrm{Ba}$ that ranged from 0.700 to $73.2 \%$. In general, increasing the sonication time, along with increasing the volume of this reagent, moderately enhanced the extraction efficiency of the metals studied.

\subsubsection{Influence of $\mathrm{HNO}_{3}: \mathrm{HCl}(1: 1, \mathrm{v} / \mathrm{v})$}

Used oils extracted using $\mathrm{HNO}_{3}: \mathrm{HCl}(1: 1)$ were very light yellow in colour and yielded good analyte recoveries of $\mathrm{Cu}, \mathrm{Mn}$, and $\mathrm{Ni}$. The recoveries of $\mathrm{Ag}$ and Ba were still unsatisfactory but had improved when compared to the recoveries obtained using nitric acid alone and $\mathrm{HNO}_{3}: \mathrm{H}_{2} \mathrm{O}_{2}(2: 1)$. At constant sonication time (30 min), increasing the volume of $\mathrm{HNO}_{3}: \mathrm{HCl} / 1: 1$ from 3.00 to $10.0 \mathrm{~mL}$ caused a strong negative influence for the extraction efficency of $\mathrm{Cu}, \mathrm{Mn}$ and $\mathrm{Ni}$ and a moderate negative influence for $\mathrm{Ag}$ and $\mathrm{Ba}$. However, increasing the sonication time to $60 \mathrm{~min}$ together with an increase in the volume of $\mathrm{HNO}_{3}: \mathrm{HCl} / 1: 1$, produced a strong positive association for $\mathrm{Ag}$, $\mathrm{Ba}$ and $\mathrm{Mn}$ and moderate for $\mathrm{Cu}$ and $\mathrm{Ni}$. Recoveries of $\mathrm{Ag}, \mathrm{Cu}, \mathrm{Mn}$ and $\mathrm{Ni}$ were generally observed to increase with increasing the volume of $\mathrm{HNO}_{3}: \mathrm{HCl}(1: 1)$ from 3.00 to $10.0 \mathrm{~mL}$.

\subsubsection{Influence of Aqua Regia}

Used oil samples extracted using aqua regia $\left(\mathrm{HNO}_{3}: \mathrm{HCl} / 1: 3\right)$ gave a clear solution. As a strong oxidizing agent, aqua regia yielded good analyte recoveries of the elements studied, except for Ba (Fig. 1a-e). Further investigation revealed that under the same extraction conditions of $10.0 \mathrm{~mL}$ aqua regia and $120 \mathrm{~min}$ sonication time, the recovery of Ba increased as the spike level decreased from 5.95 to $2.33 \mu \mathrm{g} \mathrm{g}^{-1}$ (Fig. 2). The possible reason for this phenomenon lies on the limitation of the extracting agent (aqua regia) to isolate $\mathrm{Ba}$ analytes from the oil matrix as the spiked level exceeded about $0.450 \mu \mathrm{g} \mathrm{g}^{-1}$. Increasing the volume of aqua regia, while the sonication time was kept constant at $30 \mathrm{~min}$, strongly promoted the recoveries of $\mathrm{Ag}$ and $\mathrm{Ba}$. At the same time, it strongly suppressed the recoveries of $\mathrm{Cu}$ and $\mathrm{Mn}$. When the sonication time was raised to $60 \mathrm{~min}$; the recovery of $\mathrm{Ag}$, $\mathrm{Ba}$ and $\mathrm{Mn}$ was highly increased with increasing the 


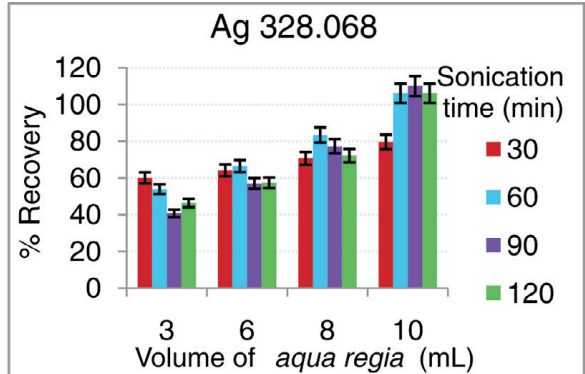

(a)

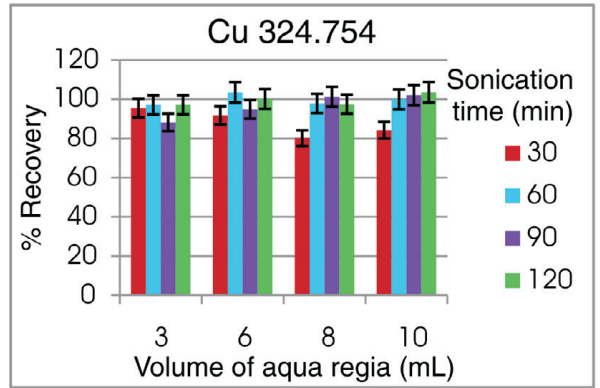

(c)

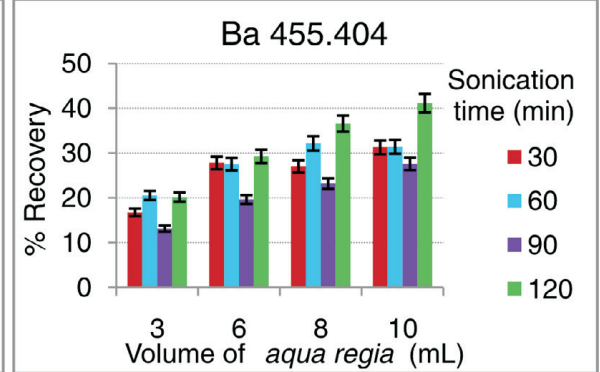

(b)

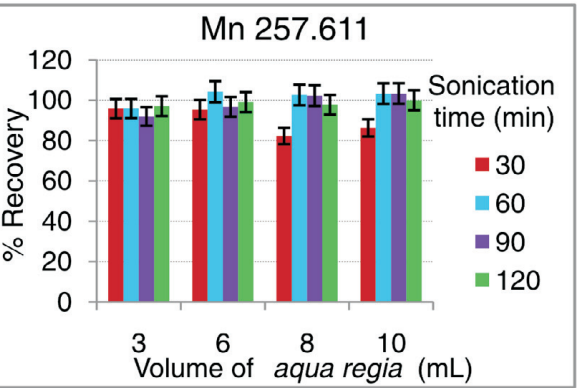

(d)

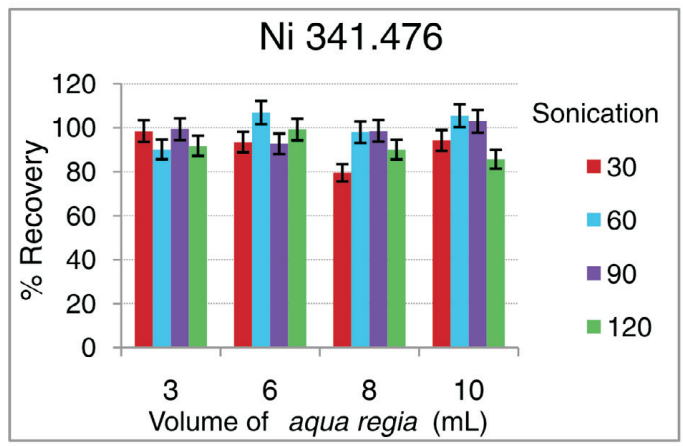

(e)

Figure 1 Influence of aqua regia on the extraction of (a) $\mathrm{Ag}$, (b) $\mathrm{Ba},(\mathbf{c}) \mathrm{Cu}$, (d) $\mathrm{Mn}$, and (e) $\mathrm{Ni}$, in used oils $(n=3)$.

volume of aqua regia. Generally, a simultaneous increase in aqua regia volume and sonication time resulted in a better extraction efficiency for all the elements studied.

The recovery of Ag was shown to increase significantly with an increase in the volume of aqua regia from 3.00 to $10.0 \mathrm{~mL}$ (Fig. 1a). The increase in volume of aqua regia possibly has introduced more chloride ions into the solution, which might contribute to the formation of silver anionic complex $\left(\mathrm{AgCl}_{\mathrm{x}}^{1-x}\right)$ in solution, rather than a precipitate of $\mathrm{AgCl}$. For this content, concentra-

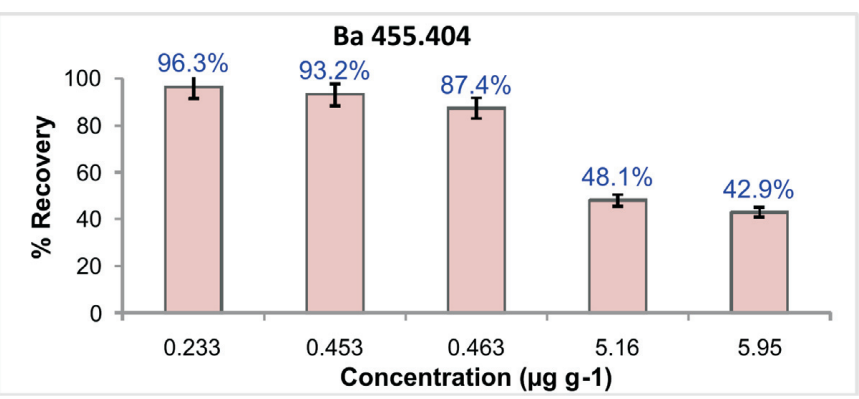

Figure 2 Ultrasonic extraction of Ba under constant conditions of $10.0 \mathrm{~mL}$ aqua regia and 120 min sonication time $(n=3)$. tions of $\mathrm{Ag}$ ranging from 0 to $10.0 \mu \mathrm{g} \mathrm{g}^{-1}$ in $25 \%$ aqua regia $(\mathrm{v} / \mathrm{m})$ formed a clear solution and hence resulted in a good linearity $\left(r^{2}=0.99993\right)$, as depicted in Fig. 3. In contrast, calibration standards containing 25.0 and $50.0 \mu \mathrm{g} \mathrm{g}^{-1}$ of $\mathrm{Ag}$ in $25 \%$ aqua regia $(\mathrm{v} / \mathrm{m})$ were shown to form more precipitates of $\mathrm{AgCl}$, and hence significantly deviated from the certified values $\left(r^{2}=0.93116\right)$. These results may imply that a reasonably low concentration of $\mathrm{Ag}$ is unlikely to form precipitate if kept in excess aqua regia.

\subsubsection{Influence of Sonication Time}

The effect of sonication time for the extraction of analytes in used lubricating oils was studied at 30, 60, 90 and 120 min. Increasing the sonication time was shown to increase the temperature of the bath $\left(62^{\circ} \mathrm{C}\right.$ max), and hence the sample solution. When nitric acid was used as extractant, increasing the sonication time was generally observed to depress the recoveries of $\mathrm{Ba}$ and $\mathrm{Ni}$; but was enhanced for $\mathrm{Ag}$. Increasing the sonication time, during extraction with $\mathrm{HNO}_{3}: \mathrm{H}_{2} \mathrm{O}_{2}(2: 1)$, generally increased the recoveries of $\mathrm{Ag}, \mathrm{Cu}$ and $\mathrm{Mn}$. When using low volumes of extracting reagents, usually 3.00 to $6.00 \mathrm{~mL}$, increasing the sonication time was shown to have a slight influence on the extraction efficiency of the elements studied. Similarly, increas- 

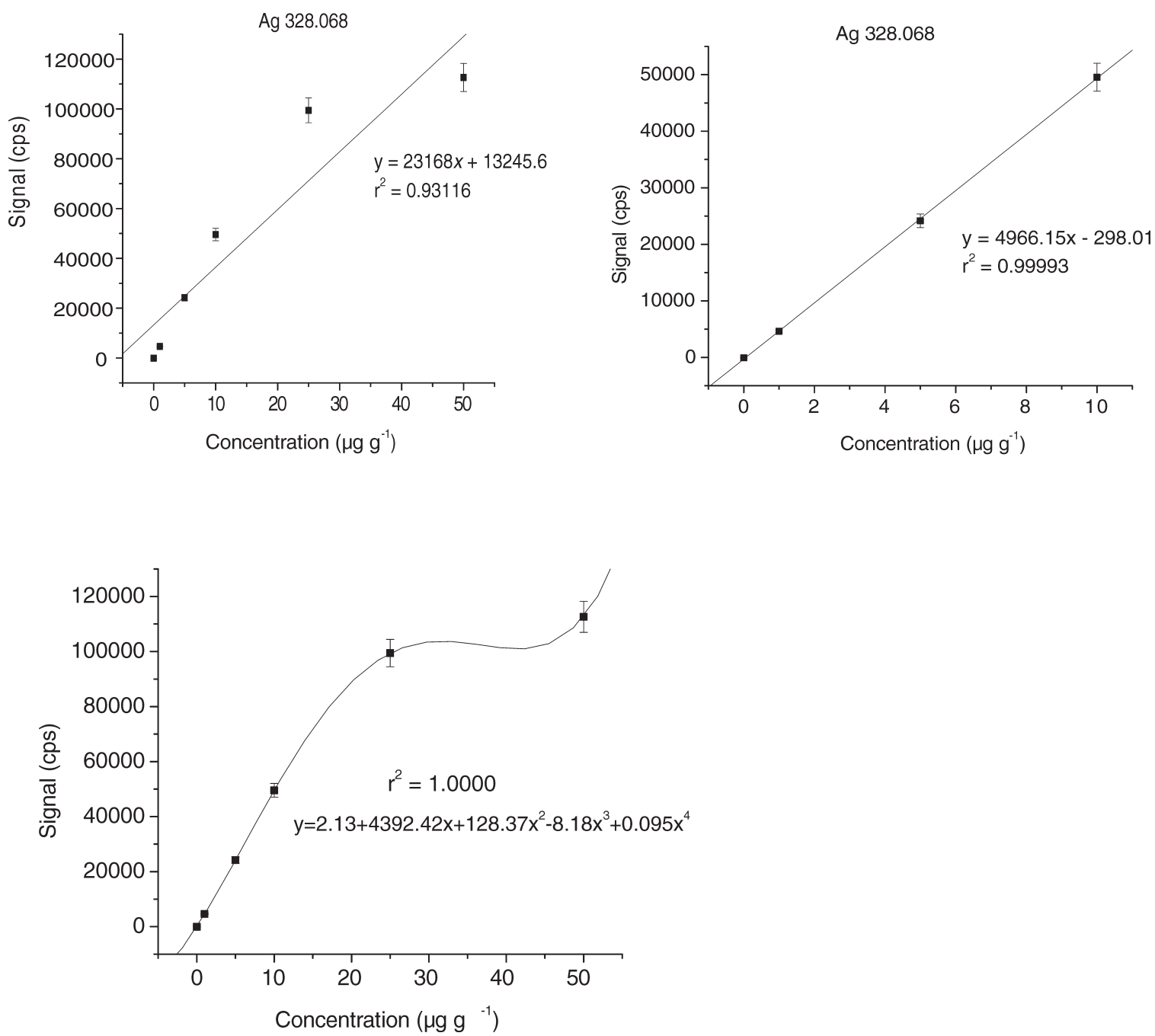

Figure 3 Calibration curves constructed with $0-50.0 \mu \mathrm{g} \mathrm{g}^{-1}$ of $\mathrm{Ag}$ in $25 \%(\mathrm{~m} / \mathrm{v})$ aqua regia $(n=3)$.

ing the sonication time, employing 3.00 to $8.00 \mathrm{~mL}$ of aqua regia and $\mathrm{HNO}_{3}: \mathrm{HCl}(1: 1)$ was observed to depress the recovery of $\mathrm{Ag}$. A simultaneous increase in sonication time and concentration of the extracting reagents was generally found to enhance the extracting efficiency of the elements studied. This was critical, particularly when aqua regia and $\mathrm{HNO}_{3}: \mathrm{HCl}(1: 1)$ were used as extracting agents.

\subsection{Figures of Merit and Validation}

The limits of detection, LOD $\left(3 S_{b} / \mathrm{m}\right.$, where $S_{\mathrm{b}}$ is the standard deviation of 10 replicates of blank solutions and $m$ the sensitivity) and limits of quantitation, LOQ $\left(10 S_{b} / \mathrm{m}\right)$ were computed for each element and they were in the low $\mathrm{ng} \mathrm{g}^{-1}$ range (Table 3 ), which will easily permit the determination of trace levels of wear metals and trends to be observed. Microwave digestion and dry-ashing methods offered much better LOD and LOQ when compared with the other methods investigated.

A certified reference material (CRM) in used oil and organo-metallic standard were analyzed by ICP-OES. The quantitative data obtained from both quality control (QC) samples was used to compute the accuracy of each studied method. The recoveries obtained from both QC samples were comparable for most of the studied elements, as shown in Tables 4 and 5. Applying the Student's $t$-test to these data indicated good agreement between the certified and measured values at the $95 \%$ confidence level, for most of the elements studied.

Each of the six analytical methods investigated were validated based on the criteria illustrated in Table 6 and the method of choice for the determination of $\mathrm{Mn}$ was microwave digestion; for $\mathrm{Cu}$, xylene dilution; for $\mathrm{Ba}$, wet-ashing; for $\mathrm{Ni}$, oil emulsification and for Ag ultrasonic extraction. The methods investigated were further evaluated in terms of suitability for routine analysis, sample preparation time and cost (approximate cost of reagents and instrument running costs). Based on these evaluations, an ultrasonic extraction has a clear advantage in terms of accuracy, cost of sample preparation, simplicity, safety and suitability for routine analysis.

\subsection{Evaluation of Sample Preparation Methods}

\subsubsection{Xylene Dilution Method}

The dilution method required the use of organo-metallic standards for calibration, which were expensive when compared to inorganic standards. This technique did not minimize the organic load of the oil and hence plasma stability was a concern and which demanded careful optimization of the gas flow rates. The choice of special sample tubes that can withstand organic solvents also contributed to an additional cost of this method. On the other hand, the dilution method offered minimal sample contamination; good accuracy (97.2-99.7\%); good precision (0.591-2.85 \% RSD), except for Ba $(7.03 \%)$; good LOQs (7.32-86.8 $\left.\mathrm{ng} \mathrm{g}^{-1}\right)$ and good linearity with $r^{2}$ ranging from 0.9996 to 0.9998 . It was also easier to handle, cheaper and rapid and hence it can be applied for routine analysis. 
Table 3 Radial ICP-OES limits of detection and quantitation of the trace elements investigated $(n=10)$.

\begin{tabular}{|c|c|c|c|c|c|c|}
\hline Method & $\begin{array}{c}\text { Parameter } \\
\left(/ \mathrm{ng} \mathrm{g}^{-1}\right)\end{array}$ & $\begin{array}{c}\mathrm{Ag} \\
(328.068)\end{array}$ & $\begin{array}{c}\text { Ba } \\
(455.404)\end{array}$ & $\begin{array}{c}\mathrm{Cu} \\
(324.754)\end{array}$ & $\begin{array}{c}\mathrm{Mn} \\
(257.611)\end{array}$ & $\begin{array}{c}\mathrm{Ni} \\
(341.476)\end{array}$ \\
\hline Xylene dilution & $\begin{array}{l}\text { LOD } \\
\text { LOQ }\end{array}$ & $\begin{array}{c}5.38 \\
17.9\end{array}$ & $\begin{array}{l}8.24 \\
27.5\end{array}$ & $\begin{array}{l}2.97 \\
9.91\end{array}$ & $\begin{array}{l}2.20 \\
7.32\end{array}$ & $\begin{array}{l}26.0 \\
86.8\end{array}$ \\
\hline Microwave digestion & $\begin{array}{l}\text { LOD } \\
\text { LOQ }\end{array}$ & $\begin{array}{l}1.92 \\
6.38\end{array}$ & $\begin{array}{l}1.07 \\
3.58\end{array}$ & $\begin{array}{l}6.92 \\
23.1\end{array}$ & $\begin{array}{l}1.16 \\
3.85\end{array}$ & $\begin{array}{l}18.0 \\
60.2\end{array}$ \\
\hline Emulsion & $\begin{array}{l}\text { LOD } \\
\text { LOQ }\end{array}$ & $\begin{array}{c}4.79 \\
16.0\end{array}$ & $\begin{array}{l}4.06 \\
13.5\end{array}$ & $\begin{array}{l}4.36 \\
14.5\end{array}$ & $\begin{array}{l}1.18 \\
3.92\end{array}$ & $\begin{array}{l}20.6 \\
68.7\end{array}$ \\
\hline Dry-ashing & $\begin{array}{l}\text { LOD } \\
\text { LOQ }\end{array}$ & $\begin{array}{l}1.79 \\
5.96\end{array}$ & $\begin{array}{l}0.904 \\
3.01\end{array}$ & $\begin{array}{l}12.7 \\
42.3\end{array}$ & $\begin{array}{l}1.36 \\
4.55\end{array}$ & $\begin{array}{c}5.60 \\
18.7\end{array}$ \\
\hline Wet-ashing & $\begin{array}{l}\text { LOD } \\
\text { LOQ }\end{array}$ & $\begin{array}{l}4.50 \\
15.0\end{array}$ & $\begin{array}{l}2.87 \\
9.56\end{array}$ & $\begin{array}{c}8.14 \\
27.1\end{array}$ & $\begin{array}{c}3.32 \\
11.1\end{array}$ & $\begin{array}{l}15.4 \\
51.4\end{array}$ \\
\hline Ultrasonic extraction & $\begin{array}{l}\text { LOD } \\
\text { LOQ }\end{array}$ & $\begin{array}{c}4.13 \\
13.8\end{array}$ & $\begin{array}{l}2.36 \\
7.87\end{array}$ & $\begin{array}{r}35.1 \\
117.0\end{array}$ & $\begin{array}{l}2.64 \\
8.79\end{array}$ & $\begin{array}{l}22.9 \\
76.2\end{array}$ \\
\hline
\end{tabular}

\subsubsection{Oil Emulsification Method}

The oil-in-water emulsion required sequential sample preparation and small sample size so as to form a stable and homogenous emulsion. It was often difficult to form stable and homogenous emulsions with matched viscosity, particularly for viscous oils. In contrast, it was cheap and fast, allowed aqueous standards for calibration and gave good linearity with $r^{2}$ ranging from 0.9998 to 1.000 . This method yielded good analyte recoveries (86.4-99.3\%) for all the elements studied when additions of Conostan standards were used. However, it yielded unsatisfactory recoveries for $\mathrm{Ag}$ and $\mathrm{Ba}$ in the CRM. This variation in accuracy might have occurred due to the low level of these elements in the CRM. The precision of results determined for this method were fairly good, with \% RSDs ranging from 1.53 to $4.99 \%$. The calculated LOQs were in the range of 3.92 to $68.7 \mathrm{ng} \mathrm{g}^{-1}$. These LOQ values imply that the method could be used for the determination of trace levels of wear metals in lubricating oils.

\subsubsection{Microwave-assisted Acid Digestion Method}

The pressurized microwave digestion gave complete digestion of oil samples, which could easily be aspirated into the ICP-discharge. The closed microwave digestion technique offered minimal sample contamination, good precision $(0.467-3.63 \%$ RSD) and good accuracy (95.6-104\%), except for Ag (50.4\%). The LODs for this method were low, ranging from 1.07 to $18.0 \mathrm{ng} \mathrm{g}^{-1}$. In contrast, the initial and running costs of the microwave apparatus were high, which could limit its use for routine analysis. The limited organic sample size recommended for digestion was also a major drawback as it may not have resulted in a representative sample. In addition, this method is moderately unsafe due to the probability of vessel explosion caused by faults such as: vessel leaks, sample size, sample matrix and operator's error.

\subsubsection{Dry-ashing Method}

The dry-ashing method completely mineralized the oil matrix and resulted in a clear solution, which could be easily aspirated

Table 4 Mean recoveries ( \pm S.D.) obtained from the analysis of EnviroMAT (certified reference material in used oil) by ICP-OES $(n=3)$.

\begin{tabular}{|c|c|c|c|c|c|c|}
\hline Method & Description & $\frac{\mathrm{Ag}}{/ \mu \mathrm{g} \mathrm{g}^{-1}}$ & $\begin{array}{c}\mathrm{Ba} \\
/ \mu \mathrm{g} \mathrm{g}^{-1}\end{array}$ & $\frac{\mathrm{Cu}}{/ \mu \mathrm{g} \mathrm{g}^{-1}}$ & $\begin{array}{l}\mathrm{Mn} \\
/ \mu \mathrm{g} \mathrm{g}^{-1}\end{array}$ & $\begin{array}{c}\mathrm{Ni} \\
/ \mu \mathrm{g} \mathrm{g}^{-1}\end{array}$ \\
\hline Xylene dilution & $\begin{array}{l}\text { Certified } \\
\text { Obtained } \\
\% \text { Recovered }\end{array}$ & $\begin{array}{c}13.0 \\
2.21 \pm 0.13 \\
\mathbf{1 7 . 0} \pm \mathbf{1 . 2 ^ { \mathrm { a } }}\end{array}$ & $\begin{array}{c}9.00 \\
9.22 \pm 0.85 \\
102 \pm 7.2^{\mathrm{b}}\end{array}$ & $\begin{array}{c}3132 \\
3312 \pm 26 \\
106 \pm 3.0\end{array}$ & $\begin{array}{c}18.00 \\
14.5 \pm 0.31 \\
\mathbf{8 0 . 3} \pm \mathbf{3 . 2}\end{array}$ & $\begin{array}{c}45.0 \\
37.5 \pm 0.70 \\
83.3 \pm \mathbf{3 . 3}\end{array}$ \\
\hline Emulsion & $\begin{array}{l}\text { Certified } \\
\text { Obtained } \\
\% \text { Recovered }\end{array}$ & $\begin{array}{c}13.0 \\
3.93 \pm 0.36 \\
30.2 \pm 2.5\end{array}$ & $\begin{array}{c}9.00 \\
4.35 \pm 0.25 \\
48.3 \pm 2.3^{c}\end{array}$ & $\begin{array}{c}3132 \\
3290 \pm 191 \\
105 \pm 5.2\end{array}$ & $\begin{array}{c}18.00 \\
13.3 \pm 0.79 \\
73.6 \pm 3.5\end{array}$ & $\begin{array}{c}45.0 \\
43.2 \pm 1.6 \\
96.0 \pm 3.2\end{array}$ \\
\hline $\begin{array}{l}\text { Microwave } \\
\text { digestion }\end{array}$ & $\begin{array}{l}\text { Certified } \\
\text { Obtained } \\
\% \text { Recovered }\end{array}$ & $\begin{array}{c}13.0 \\
6.55 \pm 0.08 \\
\mathbf{5 0 . 4} \pm \mathbf{1 . 4}\end{array}$ & $\begin{array}{c}9.00 \\
8.62 \pm 0.27 \\
96.2 \pm 0.64\end{array}$ & $\begin{array}{c}3132 \\
3250 \pm 5.2 \\
104 \pm 3.8\end{array}$ & $\begin{array}{c}18.0 \\
18.5 \pm 0.68 \\
103 \pm 0.48\end{array}$ & $\begin{array}{c}45.0 \\
43.0 \pm 1.7 \\
95.6 \pm 2.6\end{array}$ \\
\hline Dry-ashing & $\begin{array}{l}\text { Certified } \\
\text { Obtained } \\
\% \text { Recovered }\end{array}$ & $\begin{array}{c}13.0 \\
2.34 \pm 0.15 \\
18.0 \pm 2.9\end{array}$ & $\begin{array}{c}9.00 \\
9.20 \pm 0.32 \\
102 \pm 6.4\end{array}$ & $\begin{array}{c}3132 \\
3170 \pm 120 \\
101 \pm 5.9\end{array}$ & $\begin{array}{c}18.0 \\
14.8 \pm 1.2 \\
\mathbf{8 1 . 9} \pm \mathbf{1 . 7}\end{array}$ & $\begin{array}{c}45.0 \\
21.8 \pm 2.5 \\
48.3 \pm 3.8\end{array}$ \\
\hline Wet-ashing & $\begin{array}{l}\text { Certified } \\
\text { Obtained } \\
\% \text { Recovered }\end{array}$ & $\begin{array}{c}13.0 \\
1.42 \pm 0.15 \\
\mathbf{1 0 . 9} \pm \mathbf{1 . 2}\end{array}$ & $\begin{array}{c}9.00 \\
8.56 \pm 0.03 \\
95.1 \pm 1.0\end{array}$ & $\begin{array}{c}3132 \\
3310 \pm 67 \\
106 \pm 1.2\end{array}$ & $\begin{array}{c}18.0 \\
18.9 \pm 0.84 \\
105 \pm 4.8\end{array}$ & $\begin{array}{c}45.0 \\
42.9 \pm 4.2 \\
95.2 \pm 9.0\end{array}$ \\
\hline $\begin{array}{l}\text { Ultrasonic } \\
\text { extraction }\end{array}$ & $\begin{array}{l}\text { Certified } \\
\text { Obtained } \\
\% \text { Recovered }\end{array}$ & $\begin{array}{c}13.0 \\
6.29 \pm 0.17 \\
\mathbf{4 8 . 4} \pm \mathbf{0 . 7}\end{array}$ & $\begin{array}{c}9.00 \\
8.67 \pm 0.47 \\
96.3 \pm 2.4\end{array}$ & $\begin{array}{c}3132 \\
3060 \pm 25 \\
97.8 \pm 2.9\end{array}$ & $\begin{array}{c}18.0 \\
14.3 \pm 0.84 \\
79.5 \pm 2.2\end{array}$ & $\begin{array}{c}45.0 \\
46.0 \pm 4.6 \\
102 \pm 13\end{array}$ \\
\hline
\end{tabular}

${ }^{\text {a }}$ Recovery values in bold fall within the tolerance interval (TI) adopted (95\%).

${ }^{\mathrm{b}}$ Recovery values in normal print fall within the confidence limit (CL) adopted (95\%).

${ }^{\mathrm{c}}$ Recovery values in italics fall outside the TI adopted (95\%). 
Table 5 Mean recoveries ( \pm S.D.) obtained from the analysis of organo-metallic standard (Conostan S-21) by ICP-OES $(n=3)$.

\begin{tabular}{|c|c|c|c|c|c|c|}
\hline Method & Description & $\underset{/ \mu \mathrm{g} \mathrm{g}^{-1}}{\mathrm{Ag}}$ & $\begin{array}{c}\mathrm{Ba} \\
/ \mu \mathrm{g} \mathrm{g}^{-1}\end{array}$ & $\begin{array}{c}\mathrm{Cu} \\
/ \mu \mathrm{g} \mathrm{g}^{-1}\end{array}$ & $\underset{/ \mu \mathrm{g} \mathrm{g}^{-1}}{\mathrm{Mn}}$ & $\begin{array}{c}\mathrm{Ni} \\
/ \mu \mathrm{g} \mathrm{g}^{-1}\end{array}$ \\
\hline Dilution & $\begin{array}{l}\text { Spiked } \\
\text { Obtained } \\
\text { \% Recovered }\end{array}$ & $\begin{array}{c}500 \\
497 \pm 11 \\
99.3 \pm 2.2\end{array}$ & $\begin{array}{c}500 \\
486 \pm 17 \\
97.2 \pm 3.5\end{array}$ & $\begin{array}{c}500 \\
494 \pm 7.1 \\
98.8 \pm 1.4\end{array}$ & $\begin{array}{c}500 \\
489 \pm 4.2 \\
97.8 \pm 0.84\end{array}$ & $\begin{array}{c}500 \\
498 \pm 2.9 \\
99.7 \pm 0.59\end{array}$ \\
\hline Emulsion & $\begin{array}{l}\text { Spiked } \\
\text { Obtained } \\
\text { \% Recovered }\end{array}$ & $\begin{array}{c}500 \\
432 \pm 5.8 \\
86.4 \pm 1.3\end{array}$ & $\begin{array}{c}500 \\
456 \pm 11 \\
91.1 \pm 2.4\end{array}$ & $\begin{array}{c}500 \\
462 \pm 2.3 \\
92.3 \pm 0.62\end{array}$ & $\begin{array}{c}500 \\
497 \pm 11 \\
99.3 \pm 2.3\end{array}$ & $\begin{array}{c}500 \\
471 \pm 2.9 \\
94.0 \pm 0.75\end{array}$ \\
\hline Microwave & $\begin{array}{l}\text { Spiked } \\
\text { Obtained } \\
\text { \% Recovered }\end{array}$ & $\begin{array}{c}500 \\
27.1 \pm 1.3 \\
5.41 \pm 0.30\end{array}$ & $\begin{array}{c}500 \\
447 \pm 8.7 \\
89.4 \pm 1.7\end{array}$ & $\begin{array}{c}500 \\
464 \pm 8.9 \\
92.8 \pm 1.8\end{array}$ & $\begin{array}{c}500 \\
521 \pm 8.2 \\
104 \pm 1.6\end{array}$ & $\begin{array}{c}500 \\
460 \pm 7.6 \\
92.0 \pm 1.5\end{array}$ \\
\hline Dry-ashing & $\begin{array}{l}\text { Spiked } \\
\text { Obtained } \\
\% \text { Recovered }\end{array}$ & $\begin{array}{c}500 \\
245 \pm 23 \\
48.9 \pm 5.0\end{array}$ & $\begin{array}{c}500 \\
457 \pm 22 \\
91.4 \pm 5.2\end{array}$ & $\begin{array}{c}500 \\
422 \pm 23 \\
84.4 \pm 5.5\end{array}$ & $\begin{array}{c}500 \\
411 \pm 21 \\
82.2 \pm 5.2\end{array}$ & $\begin{array}{c}500 \\
185 \pm 27 \\
36.9 \pm 5.8\end{array}$ \\
\hline Wet-ashing & $\begin{array}{l}\text { Spiked } \\
\text { Obtained } \\
\text { \% Recovered }\end{array}$ & $\begin{array}{c}500 \\
382 \pm 21 \\
76.3 \pm 4.3\end{array}$ & $\begin{array}{c}500 \\
476 \pm 30 \\
95.1 \pm 6.1\end{array}$ & $\begin{array}{c}5004 \\
33 \pm 18 \\
86.5 \pm 3.6\end{array}$ & $\begin{array}{c}500 \\
499 \pm 1.4 \\
99.7 \pm 0.27\end{array}$ & $\begin{array}{c}500 \\
100 \pm 6.2 \\
20.0 \pm 1.2\end{array}$ \\
\hline $\begin{array}{l}\text { Ultrasonic } \\
\text { extraction }\end{array}$ & $\begin{array}{l}\text { Spiked } \\
\text { Obtained } \\
\% \text { Recovered }\end{array}$ & $\begin{array}{c}500 \\
506 \pm 11 \\
101 \pm 2.3\end{array}$ & $\begin{array}{c}500 \\
241 \pm 45 \\
48.1 \pm 9.1\end{array}$ & $\begin{array}{c}500 \\
471 \pm 7.1 \\
94.2 \pm 1.4\end{array}$ & $\begin{array}{c}500 \\
501 \pm 7.1 \\
100 \pm 1.3\end{array}$ & $\begin{array}{c}500 \\
465 \pm 9.3 \\
93.1 \pm 1.8\end{array}$ \\
\hline
\end{tabular}

into the plasma. It was simple to use and control all steps of the procedure. Accuracy of the method was also moderately good (81.9-102\%), with the exception of $\mathrm{Ag}(48.9 \%)$ and $\mathrm{Ni}(48.3 \%)$. However, the precision of these results was poor, ranging from 5.80 to $16.2 \%$ RSD, except for Mn (2.06 \%). The LODs obtained by this method were low, ranging from 0.904 to $12.7 \mathrm{ng}$ $\mathrm{g}^{-1}$. On the other hand, sample preparation time was rather long (about $17 \mathrm{~h}$ ), which limits its applicability for routine analysis.

Table 6 Criteria applied for method validation.

\begin{tabular}{|c|c|c|c|c|c|c|}
\hline \multirow[t]{2}{*}{ Analytical Method } & \multirow[t]{2}{*}{ Validation criteria } & \multicolumn{5}{|c|}{ Results } \\
\hline & & $\mathrm{Ag}$ & $\mathrm{Ba}$ & $\mathrm{Cu}$ & $\mathrm{Mn}$ & $\mathrm{Ni}$ \\
\hline Xylene dilution & $\begin{array}{l}\% \text { Recovery } \\
\% \text { RSD } \\
\text { Linearity } / r^{2} \\
\text { LOD } / \mathrm{ng} \mathrm{g}^{-1} \\
\text { LOQ } / \mathrm{ng} \mathrm{g}^{-1}\end{array}$ & $\begin{array}{c}99.3 \pm 2.1 \\
2.16 \\
0.9997 \\
5.38 \\
17.9\end{array}$ & $\begin{array}{c}102 \pm 7.2 \\
7.03 \\
0.9998 \\
8.24 \\
27.5\end{array}$ & $\begin{array}{c}106 \pm 3.0 \\
2.85 \\
0.9998 \\
2.97 \\
9.91\end{array}$ & $\begin{array}{c}97.8 \pm 0.84 \\
0.862 \\
0.9996 \\
2.2 \\
7.32\end{array}$ & $\begin{array}{c}99.7 \pm 0.59 \\
0.591 \\
0.9998 \\
26.0 \\
86.8\end{array}$ \\
\hline Emulsion & $\begin{array}{l}\% \text { Recovery } \\
\% \text { RSD } \\
\text { Linearity } / r^{2} \\
\text { LOD } / \text { ng g }^{-1} \\
\text { LOQ } / \text { ng g }^{-1}\end{array}$ & $\begin{array}{c}86.4 \pm 1.3 \\
1.53 \\
0.9999 \\
4.79 \\
16.0\end{array}$ & $\begin{array}{c}91.1 \pm 2.4 \\
2.66 \\
0.9998 \\
4.06 \\
13.5\end{array}$ & $\begin{array}{c}105 \pm 5.2 \\
4.99 \\
1.0000 \\
4.36 \\
14.5\end{array}$ & $\begin{array}{c}99.3 \pm 2.3 \\
2.35 \\
0.9999 \\
1.18 \\
3.92\end{array}$ & $\begin{array}{c}96.0 \pm 3.2 \\
3.30 \\
0.9999 \\
20.6 \\
68.7\end{array}$ \\
\hline Microwave digestion & $\begin{array}{l}\% \text { Recovery } \\
\% \text { RSD } \\
\text { Linearity } / r^{2} \\
\text { LOD } / \text { ng g }^{-1} \\
\text { LOQ } / \text { ng g }^{-1}\end{array}$ & $\begin{array}{c}50.4 \pm 1.4 \\
2.72 \\
0.9999 \\
1.92 \\
6.39\end{array}$ & $\begin{array}{c}96.2 \pm 0.64 \\
0.669 \\
0.9997 \\
1.07 \\
3.58\end{array}$ & $\begin{array}{c}104 \pm 3.8 \\
3.63 \\
1.0000 \\
6.92 \\
23.1\end{array}$ & $\begin{array}{c}103 \pm 0.48 \\
0.467 \\
0.9999 \\
1.16 \\
3.85\end{array}$ & $\begin{array}{c}95.6 \pm 2.6 \\
2.71 \\
0.9997 \\
18.0 \\
60.2\end{array}$ \\
\hline Dry-ashing & $\begin{array}{l}\% \text { Recovery } \\
\% \text { RSD } \\
\text { Linearity } / r^{2} \\
\text { LOD } / \text { ng g }^{-1} \\
\text { LOQ } / \text { ng g }^{-1}\end{array}$ & $\begin{array}{c}48.9 \pm 5.0 \\
16.2 \\
0.9998 \\
1.79 \\
5.96\end{array}$ & $\begin{array}{c}102 \pm 6.4 \\
6.33 \\
0.9998 \\
0.904 \\
3.01\end{array}$ & $\begin{array}{c}101 \pm 5.9 \\
5.80 \\
1.0000 \\
12.7 \\
42.3\end{array}$ & $\begin{array}{c}81.9 \pm 1.7 \\
2.06 \\
0.9999 \\
1.36 \\
4.55\end{array}$ & $\begin{array}{c}48.3 \pm 3.8 \\
7.89 \\
1.0000 \\
5.60 \\
18.7\end{array}$ \\
\hline Wet-ashing & $\begin{array}{l}\% \text { Recovery } \\
\% \text { RSD } \\
\text { Linearity } / r^{2} \\
\text { LOD } / \text { ng g }^{-1} \\
\text { LOQ } / \text { ng g }^{-1}\end{array}$ & $\begin{array}{c}76.3 \pm 4.3 \\
5.62 \\
0.9999 \\
4.50 \\
15.0\end{array}$ & $\begin{array}{c}95.1 \pm 1.1 \\
1.10 \\
0.9999 \\
2.87 \\
9.56\end{array}$ & $\begin{array}{c}106 \pm 1.2 \\
1.15 \\
1.0000 \\
8.14 \\
27.1\end{array}$ & $\begin{array}{c}105 \pm 4.8 \\
4.57 \\
0.9997 \\
3.32 \\
11.1\end{array}$ & $\begin{array}{c}95.2 \pm 9.0 \\
9.47 \\
0.9998 \\
15.4 \\
51.4\end{array}$ \\
\hline Ultrasonic extraction & $\begin{array}{l}\text { \% Recovery } \\
\% \text { RSD } \\
\text { Linearity } / r^{2} \\
\text { LOD } / \text { ng g }^{-1} \\
\text { LOQ } / \text { ng g }^{-1}\end{array}$ & $\begin{array}{c}101 \pm 2.3 \\
2.26 \\
0.9997 \\
4.13 \\
13.8\end{array}$ & $\begin{array}{c}96.3 \pm 2.4 \\
2.49 \\
0.9997 \\
2.36 \\
7.87\end{array}$ & $\begin{array}{c}97.8 \pm 2.9 \\
2.97 \\
1.0000 \\
35.1 \\
117\end{array}$ & $\begin{array}{c}100 \pm 1.3 \\
2.76 \\
1.0000 \\
2.64 \\
8.79\end{array}$ & $\begin{array}{c}102 \pm 13 \\
12.6 \\
0.9999 \\
22.9 \\
76.2\end{array}$ \\
\hline
\end{tabular}


This long and open-air sample heating can obviously cause sample contamination, which is a major concern in trace metal analysis. Loss of some volatile analytes during the intense heating and muffling was a major concern. Consequently, a significant loss of $\mathrm{Ni}$ for both types of additions occurred and this resulted in reduction of $\mathrm{Ni}$ recovery from 49.8 to $7.67 \%$ as the spiked level increased from 1.18 to $10.0 \mu \mathrm{g} \mathrm{g}^{-1}$. Hence the dry-ashing technique was found to be inefficient for the determination of $\mathrm{Ni}$.

\subsubsection{Wet-ashing Method}

The wet-ashing method completely destroyed the oil matrix and resulted in a clear solution. When compared to dry-ashing, the wet-ashing method offered a relatively short sample preparation time, taking $6 \mathrm{~h}$ ( $2 \mathrm{~h}$ heating to dryness and $4 \mathrm{~h}$ muffling). Sample heating and muffling employed in both dry and wetashing procedures were relatively inexpensive when compared to the microwave digestion procedure. Hence, the wet-ashing approach can be used for routine analysis of oils, as an alternative method to microwave digestion. This technique generated lower LODs (2.87-15.4 $\left.\mathrm{ng} \mathrm{g}^{-1}\right)$, good accuracy (95.1-106 \%), except for Ag (76.3\%) and good precision (1.10-5.62 \% RSD), except for $\mathrm{Ni}(9.47 \%)$. Like dry-ashing, wet-ashing also yielded a poor recovery of $\mathrm{Ni}(38.7 \%)$ when only nitric acid was used as oxidizing agent. Nonetheless, wet-ashing, employed concentrated sulphuric acid as oxidant, followed by nitric acid dissolution, minimized Ni losses and offered better recovery that fell within the confidence limit adopted $(95 \%)$. It is possible that $\mathrm{Ni}$ was retained as non-volatile NiS, which is sparingly soluble in nitric acid. This phenomenon is in agreement with the finding of Aucelio et al. ${ }^{19}$ Another interesting observation in the analysis of the QC samples, containing around $1 \mu \mathrm{g} \mathrm{g}^{-1}$ of $\mathrm{Ni}$, ashed using $2.00 \mathrm{~mL}$ of sulphuric acid, yielded a better recovery for $\mathrm{Ni}$ $(95.2 \%)$. However, increasing the concentration of $\mathrm{Ni}$ to $5.79 \mu \mathrm{g}$ $\mathrm{g}^{-1}$, using the same ashing conditions, resulted in an abrupt loss of $\mathrm{Ni}$ (loss of $80 \%$ ). This phenomenon may indicate the need for optimizing the quantity of sulphuric acid that can efficiently retain a given concentration of Ni. Sample contamination, formation of $\mathrm{AgCl}$ and $\mathrm{BaSO}_{4}$ precipitate when hydrochloric and sulphuric acids were used, and loss of $\mathrm{Ni}$ when nitric acid was used as oxidizing agent, sample loss due to foaming and sample adsorption into the porcelain crucibles were some major observed limitations for the wet-ashing technique.

\subsubsection{Ultrasound-assisted Extraction}

The ultrasound extraction approach, employing extractant reagents, was effective for the extraction of metals from used lubricating oils. An ultrasonic bath is inexpensive and simple to operate. The reaction vessels (volumetric flasks) employed were also inexpensive and available in any laboratory. The extraction procedure is safe and simple to handle, and required $2 \mathrm{~h}$. This technique offered good accuracy (96.3-102\%), good precision (2.26-2.97\% RSD), except for Ni (12.6\%) and low LODs (2.36-35.1 $\left.\mathrm{ng} \mathrm{g}^{-1}\right)$. However, the uneven distribution of the ultrasonic energy within the bath, which created cavitational variations, was found to be a major limitation of this technique. Consequently, only four samples were used in each batch to guarantee maximum ultrasonic irradiations. Even so, the ultrasonic extraction approach can be applied for routine analysis of oils for its low cost, fairly short sample preparation time, simple procedure and fairly good accuracy.

\section{Conclusions}

The recoveries obtained by ultrasonic-assisted extraction technique were quantitative, presenting values better than $93 \%$.
Such values denote that the ultrasonic extraction procedure, proposed in this work, is efficient in destroying the organic matrix, allowing for the releasing of metals. It was demonstrated that the most important interaction between variables occurred when a simultaneous increase in sonication time (30-120 min) and volume of the extracting reagent $(3.00-10.0 \mathrm{~mL})$ was applied. This was critical, particularly when $\mathrm{HNO}_{3}: \mathrm{HCl}(1: 1, \mathrm{v} / \mathrm{v})$ and $\mathrm{HNO}_{3}: \mathrm{HCl}(1: 3, \mathrm{v} / \mathrm{v})$, were used as extracting reagents. Furthermore, aqua regia was found to be the most powerful and universal extracting reagent for all metals studied.

The results obtained from the analysis of additions of both organo-metallic standard (Conostan S-21) and CRM by ICP-OES, permitted validation of each method studied with respect to its accuracy, precision, linearity, LOD and LOQ. Based on these evaluations, the choice of method for the determination of $\mathrm{Mn}$ in used oils was microwave digestion, for $\mathrm{Ba}$, wet-ashing; for $\mathrm{Cu}$, xylene dilution; for $\mathrm{Ni}$, detergent emulsion and for $\mathrm{Ag}$, ultrasonic extraction. Further evaluation of the methods in terms of suitability for routine analysis, sample preparation time and cost (cost of reagents and instrumental running costs) indicated the technique of ultrasound extraction has a clear advantage in terms of accuracy, cost of sample preparation, simplicity for use, safety and suitability for routine analysis. In general, evaluation of the six analytical methods investigated (xylene dilution, detergent emulsion, microwave digestion, dry-ashing, wet-ashing and ultrasonic extraction) for the determination of trace elements in used lubricating oils showed significant differences when statistically compared using the analysis of variance (ANOVA) at the $95 \%$ confidence level.

\section{Acknowledgements}

The authors gratefully acknowledge Tshwane University of Technology and NRF for funding this project.

\section{References}

1 R.O. Aucélio, G.P. Brandão, R.C. Campos, C. Duyck, P. Grinberg, N. Miekeley and C.L.P Silveira, The determination of trace metals in lubricating oils by atomic spectrometry, Spectrochim. Acta Part B, 2007, 62, 952-961.

2 T. Kuokkanen, S. Lahdelma, K. Roppola, P. Vahaoja and I. Valimaki, Wear metal analysis of oils, Crit. Rev. Anal. Chem., 2008, 38, 67-83.

3 P.J.J.G. Marais and M.J. Orren, Application of an Argon-cooled Inductively Coupled Plasma to the Analysis of Metals in Lubricating Oils, MSc dissertation, University of Cape Town, Cape Town, South Africa, 1987.

4 B. Jeremić and I. Maćužić, Development of mobile device for oil analysis, Tribol. Indust., 2004, 26, 27-31.

5 V.R.A. Filho, and J.A.G. Neto, Evaluation of lubricating oil preparation procedures for the determination of $\mathrm{Al}, \mathrm{Ba}, \mathrm{Mo}, \mathrm{Si}$ and $\mathrm{V}$ by high-resolution continuum source FAAS, Anal. Sci., 2009, 25, 95-100.

6 I.M. Goncalves, A.M. Gonzaález and M. Murillo, Determination of metals in used lubricating oils by AAS using emulsified samples, Talanta 1998, 47, 1033-1042.

7 R.Q. Aucelio, C.L.P. da Silveira and R.M. Souza, Evaluation and validation of instrumental procedures for the determination of nickel and vanadium in fuel oils, Anal. Sci. 2004, 20, 351-355.

8 P. Yaroshchyk, R.J.S. Morrison, D. Body, and B.L. Chadwick, Quantitative determination of wear metals in engine oils using laserinduced breakdown spectroscopy: a comparison between liquid jets and static liquids, Spectrochim. Acta, Part B, 2005, 60, 986-992.

9 J. Chirinos, A. Fernandez and J. Franquiz, Multi-element optimization of the operating parameters for inductively coupled plasma atomic emission spectrometry with a charge injection device detector for the analysis of samples dissolved in organic solvents, J. Anal. At. Spectrom., 1998, 13, 995-1000.

10 R. Carpenter and L. Ebdon, A comparison of inductively coupled plasma torch - sample introduction configurations using simplex optimization, J. Anal. At. Spectrom., 1986, 1, 265-268.

11 R.M. de Souza, L.G. Leocádio, and C.L.P. da Silveira, ICP OES simul- 
taneous determination of $\mathrm{Ca}, \mathrm{Cu}, \mathrm{Fe}, \mathrm{Mg}, \mathrm{Mn}, \mathrm{Na}$, and $\mathrm{P}$ in biodiese by axial and radial inductively coupled plasma-optical emission spectrometry, Anal. Lett., 2008 41, 1615-1622.

12 E. de Oliveira, Sample preparation for atomic spectroscopy: evolution and future trends, J. Braz. Chem. Soc., 2003, 14, 174-182.

13 L.M. Costa, S.L.C. Ferreira, J.A. Nóbrega and A.R.A. Nogueira, Use of factorial design for optimization of microwave-assisted digestion of lubricating oil J. Braz. Chem. Soc., 2005, 16, 1269-1274.

14 R F.W.S. Ana, A.R. Cassella, R.J. Cassella and R.E. Santelli, Optimization of an open focused microwave oven digestion procedure for determination of metals in diesel oil by inductively coupled plasma optical emission spectrometry, J. Hazard. Mater., 2007, 149, 67-74.

15 J.L. Capelo, C. Maduro and C. Vilhena, Discussion of parameters associated with the ultrasonic solid-liquid extraction for elemental analysis (total content) by electrothermal atomic absorption spectrometry. An overview, J. Ultrason. Sonochem., 2005, 12, 225-232.
16 K. Jankowski, A. Jerzak, A. Sernicka-Poluchowicz and L. Synoradzki, Multielement determination of major elements in polymer additives by microwave induced plasma atomic emission spectrometry after microwave digestion, J. Anal. Chim. Acta, 2001, 440, 215-221.

17 A.M. Essling, D.R Huff, E.A. Huff, I.M. Fox and D.G. Graczyk, Preparation of waste oil for analysis to determine hazardous metals, ANL/ACL-95/ I, Department of Commerce, National Technical Information Service, USA, 1995, pp. 1-28.

18 R.A.A. Munoz, P.V. Oliveira, and L. Angnes, Combination of ultrasonic extraction and stripping analysis: An effective and reliable way for the determination of $\mathrm{Cu}$ and $\mathrm{Pb}$ in lubricating oils, Talanta, 2006, 68, 850-856.

19 R.Q. Aucélio, G.P. Brandão, R.C. Campos, C. Duyck, P. Grinberg, N. Miekeley and C.L.P Silveira, The determination of trace elements in crude oil and its heavy fractions by atomic spectrometry, Spectrochim. Acta, Part B, 2007a, 62, 939-951. 